\title{
Method of achieving functional correction of total abducens nerve paralysis
}

\author{
FRANK A. VESEY \\ New York, U.S.A.
}

Total permanent paralysis of the lateral rectus muscle is a rare disorder, but when we are faced with it, it presents an exasperating challenge. As time passes, the condition is aggravated by a secondary contraction of the antagonist, causing severe progressive esotropia, and the cosmetic appearance as well as muscular function become increasingly worse.

The method of Hummelsheim (1907, 1909, 1912), ingenious and imaginative as the idea was, cannot achieve the expected and sometimes-claimed good result. The numerous modifications published in the literature do not offer any real improvement over the original procedure. The best we could ever do was to achieve a good cosmetic appearance in the primary position with an abduction of $10^{\circ}(18 \triangle)$ not more than $2.5 \mathrm{~mm}$.

When we wish to analyse the cause of this failure and examine the function of a trans 8 planted strip of muscle, we must bear in mind one basic principle: any muscle, anywhere in the human body, is capable of only one simple action-contraction, which will bring the line of insertion closer to the line of origin. All the complicated primary, secondary, and tertiary actions of the extraocular muscles are merely the results of this simple function.

If we transplant an $8 \mathrm{~mm}$. long strip of half the width of the superior rectus towards the insertion of the paralysed lateral rectus (Fig. IA), the first thing we shall see is that the strip is far too short to reach the insertion. If it could act on an independent impulse, the primary action of the transplanted strip, attached to the body of the paralysed rectus,
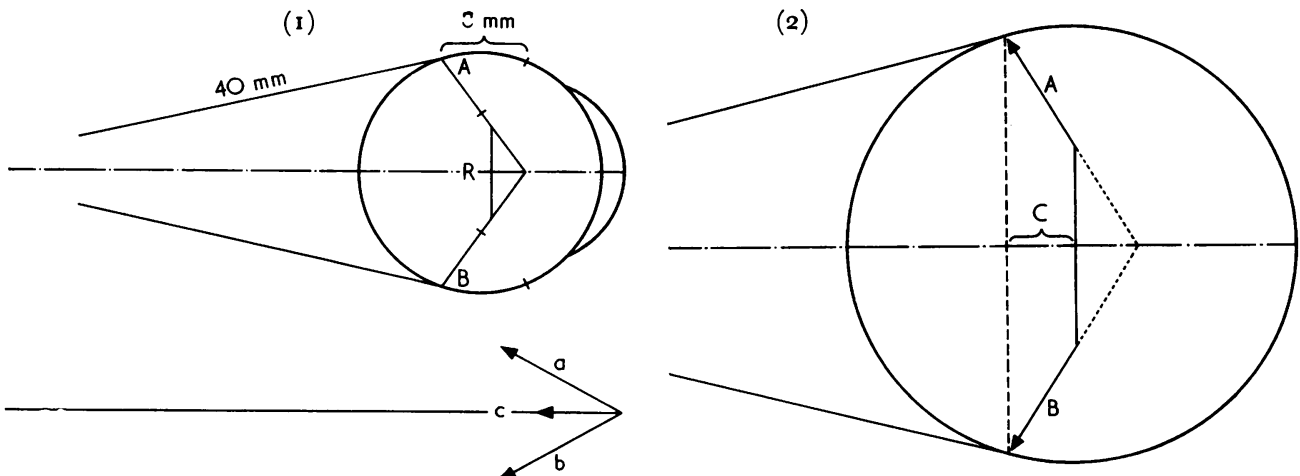

FIG. I $A$ and $B$ represent the transplanted muscle strips, which are too short to reach the insertion of the lateral rectus. $\quad a$ and $b$ are the diverging forces of the transplanted strips. $c$ is the resultant smaller force of abduction

FIG. $2 A$ and $B$ are the transplanted muscle strips. $C$ is the total possible extent of abduction, provided the strips were capable of contracting with such force as to form a straight line after contraction 
would be intorsion. The secondary action is elevation, and only the tertiary action will be abduction. A similar strip from the inferior rectus will act as antagonist to the primary and secondary action, and as synergist to the tertiary action. At the moment when the eye should start to move outwards, the primary and secondary actions would start to increase, and the desired abduction would simultaneously start decreasing.

Fig. 2A illustrates the total dynamically possible abduction.

Notwithstanding, theoretically, a total of $6 \mathrm{~mm} .=25^{\circ}=46$ prism diopters of abduction, would be possible by a transplant of a 20 to $22 \mathrm{~mm}$. long strip from the superior and/or inferior rectus (Quain and McAllister, 1889; Quain, I908-29; Scobes, I947; Stallard, 1950; Vesey, 1958, 1967).

Why is this not achieved? The reason is physiological. The function of the brain centres and pathways has been shown to be interchangeable. I refer to the experiments of Marina (1915), confirmed by Leinfelder and Black (I94I, I942) and more recently by Bloomgarden and Jampel (1963). Marina (1915) interchanged the insertions of all four rectus muscles in monkeys and in 2 weeks' time he was able to observe complete restoration of coordinated eye movements and single binocular vision, thus proving that the brain centres and pathways were capable of changing their function according to changed circumstances and changed requirements. However, an impulse to only one part of one muscle is not possible. The whole of the superior rectus, or of any other partially transplanted muscle will be stimulated, so that the little possibility of abduction will be almost completely checked.

The answer to our problem is, however, a simple one.

All we have to do is to replace the paralysed muscle with an easily available functioning one, which will have its origin and its insertion located the same way as those of the muscle we wish to replace. In the case in point, we can easily do this by transplanting the total superior rectus to the stump of the paralysed lateral rectus.

It is remarkable that nothing has to be done to replace the lost action of the transplanted superior rectus; the inferior oblique will take over completely and act as a substitute, maintaining faultless supravergence.

\section{Case report}

A 43-year-old white male patient had suffered an automobile accident 3 years before I first saw him in 1968 . He came into the room with his head turned to the extreme left, walking sideways.

\section{Examination}

There was complete paralysis of the left lateral rectus, with a pronounced secondary contraction of the left medial rectus.

\section{Operation}

The technique for the successful surgical correction of the anomaly is less complicated than a recessionresection operation:

(I) Conjunctival incision from 8 to 4 o'clock, Io $\mathrm{mm}$. from the limbus and parallel with it.

(2) Dissection of the conjunctiva from the underlying Tenon's capsule right back and forwards.

(3) Preparation of the medial rectus and release of all check-ligaments.

(4) Two myotomies, one below, one above, to lengthen the medial rectus and temporarily weaken its action. 
(5) Preparation of the lateral rectus. This will be just a thick fibrous band, if enough time has elapsed since the onset of the paralysis.

(6) Preparation of the superior rectus.

(7) Place two lock-sutures of $5-0$ chromic catgut into the medial and lateral portions of this muscle, as close to the insertion as possible. Detach the muscle from the sclera and pull down towards the insertion of the lateral rectus, to determine the length of the stump needed to unite with the superior rectus.

(8) Unite the ends of the stump and of the superior rectus by the two lock-sutures and by one placed at the centre of the cut ends.

(9) Close the conjunctival incision by a continuous 6-o black silk suture.

Resul

Good function was recovered almost immediately and the eye movements were perfect, except for a temporary weakness of the medial rectus which lasted only 2 or 3 weeks.

The appearance of the patient before and after the operation is shown in Fig. $3(a-l)$.

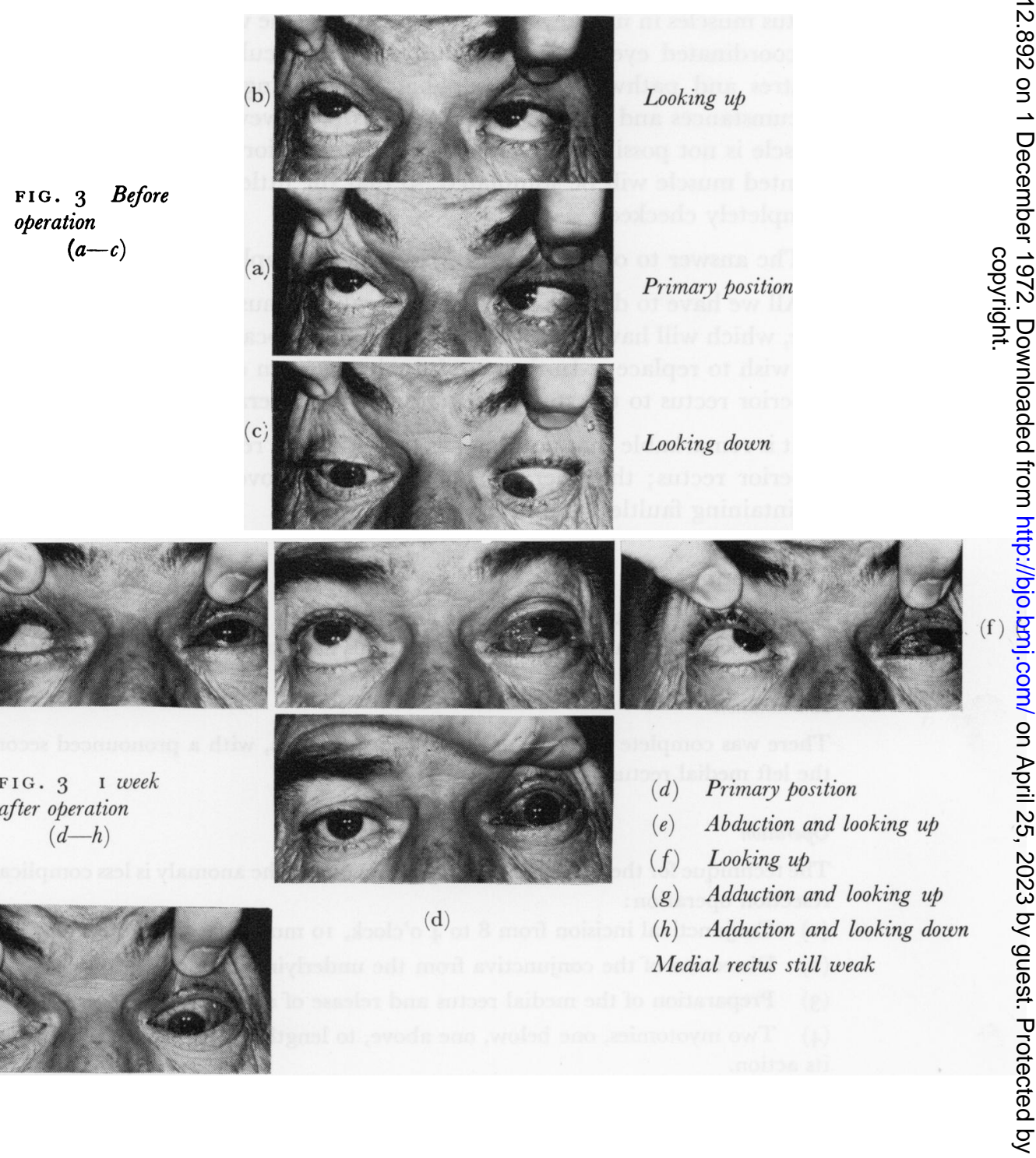


FIG. 3 (i) I month after operation $(i, j)$

FIG. 3 months after operation $(k, l)$

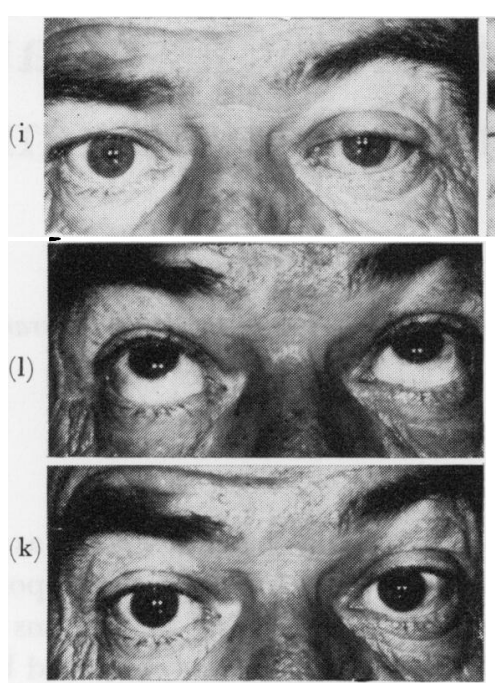

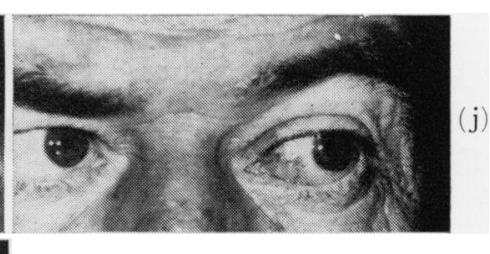

(i) Primary position

(j) Abduction

(k) Primary position

(l) Looking up

\section{Summary}

Total paralysis of the abducens nerve is a rare but crippling condition. Hitherto, the only way of obtaining a very meagre degree of relief was the method of Hummelsheim. Numerous suggested modifications offered little improvement and the best we could do was to gain a good cosmetic appearance in the primary position with a $10^{\circ}(18 \triangle)$ abduction, equal to no more than $2 \mathrm{~mm}$.

Although the function of the brain centres is interchangeable, it is impossible to stimulate only parts of a muscle, but complete restoration of a paralysed lateral rectus muscle can be obtained by replacing it with a healthy muscle stimulated by a healthy brain centre.

Abducens nerve paralysis may be overcome by transplanting the whole superior rectus to the stump of the paralysed lateral rectus; the function of the former is then taken over by the inferior oblique and normal eye movements are re-established.

\section{References}

Bloomgarden, c. I., and JAmpel, R. s. (1963) Amer. F. Ophthal., 56, 250

humMelsheim, e. (1907) Ber. dtsch. ophthal. Ges., 34, 248

- (1909) Arch. Augenheilk., 62, 7 I

- (1912) Ibid., 66, 57

LeINFELDer, P., and BLACK, N. м. (194I) Amer. F. Ophthal., 24, I I I 5

- (1942) Ibid., 25, 974

MARINA, A. (1915) Neurol. Zbl., 34, 338

QUAIN, R. (I908-29) "Quain's Elements of Anatomy", I Ith ed. Longmans Green, London

(Quoted by Whitnall, 1932)

and McAllister, A. (1889) “Text-book of Human Anatomy”. Griffin, London (Quoted

by Whitnall, 1932)

scobes, R. G. (1947) “The Oculorotary Muscles", p. 71. Mosby, St. Louis

STAllard, H. B. (1950) "Eye Surgery", 2nd ed., p. 315. Williams and Wilkins, Baltimore

vesey, F. A. (1958) Eye, Ear, Nose Thr. Mthly, 37, 5 I I

(1967) "A new method to correct complete abducens paralysis", in "XX Concilium

Ophthalmologicum Germania, I966, Acta (Münich)", vol. 2, pp. 938-942. Int. Congr. Ser.

$\mathrm{N}^{\circ}$ 146. Excerpta Medica Foundation, Amsterdam

whitnall, s. E. (I932) “The Anatomy of the Human Orbit", 2nd ed., p. 334. Oxford University

Press, London 